\title{
Design and Development of Traffic Light and IR Camera Computer Network; a Tool for Infrastructural Planning and Revenue Generation
}

\author{
Umukoro Edafewhuotu, \\ Alebu Ohimai, \\ Olugotun Olubu,
}

Dept. of Science Laboratory Tech, Auchi Polytechnic, Edo, Nigeria

Doi: 10.19044/esj.2018.v14n18p352 URL:http://dx.doi.org/10.19044/esj.2018.v14n18p352

\begin{abstract}
A traffic light is a device that gives the right of way to any road user. The device is design with three visible colours made up of the Red, Yellow and Green light. It is used to control the movement of vehicles entry or leaving a junction of a town or cities. The red colour light indicates danger or stop movement. The yellow (amber) colour indicates get ready to start or stop movement. The green light indicates crossing the intersection without danger. The infrared camera (IR) is a light emitting diode (LEDs) which can video an image in an extreme low or absence of light condition. The IR camera when installed on a traffic light will capture every vehicle image, colour and the registration number of every vehicle that is given the right of way across an intersection in various locations. The captured data can be stored in a software drive (SD-card) or the hard-disk of the computer. The traffic light and IR camera are interface with a computer network system for visible and data retrieving for further programming processing. This system when installed can be used for infrastructural planning and revenue generation for the Government. It can also be used to prevent road accident and monitor the incessant knapping of the citizen. It serves as a tool for moral discipline for road user when defaulters are persecuted and charge to pay fine. The system will eliminate manual system of controlling traffic and embarrassment caused when there is traffic jam. The system is cheap and easy to install.
\end{abstract}

Keywords: Planning, Infrastructure, Revenue generation, Traffic light, Infrared camera, Computer network

\section{Introduction}

Traffic device is an instrument used to control the traffic flow of vehicular movement of people and goods from one junction terminal to 
another on the road. With the advancement of technology, there is great increase in the number of cars and trucks on our roads. It is very alarming that the rate at which these vehicles are acquired for use on the urban roads is not proportionate to the construction of new roads or maintenance of the existing once in the cities. Hence vehicle creates a dense traffic jam on our roads and road's intersection on most axes of the cities. The means to control traffic on our major roads have been a major challenge in the transport industry. As the number of people, goods and vehicle increases daily, there is a proportionate increase in congestion of traffic. The increase in traffic congestion brings about time delay, accident, loss of life and properties. The planning of modern roads and government policies on traffic should be strictly adhere to in achieving a free flow of traffic on our highways and road intersection (Bayov, 2004). Traffic congestion may cause great disaster to the environment and the economy growth at large. But improved traffic flow will lead to an increase in the demand of goods and services which will lead to boom in the business activities of that particular region.Therefore, there is need to develop traffic device with computer networking for effective and efficient traffic control system in our urban centres to reduce traffic jam and monitor the number of vehicles and trucks plying our roads (Christina, 2014). When the system is installed, it will guide, warn and regulate road user on the right of way on intersection and this will be reduce vehicular clash on the road. Bonaventure (2011), discussed that networking traffic light devices with computer will enable the government have a statistical data in the planning of infrastructures such as construction of road, amusement, market and hospital. Also it will serves as a means of revenue generation as traffic offenders are meant to pay fine. When life and property are safe, economic activities will increase and this will lead to fast development and encourage foreign investors to a nation (Cheung et al., 2005).

Many techniques have been used including, aboveground sensors like video image processing, microwave radar, laser radar, passive infrared, ultrasonic, and passive acoustic array. However, these systems have a high equipment cost and their accuracy depends on environment conditions Another widely-used technique in conventional traffic surveillance systems is based on intrusive and non-intrusive sensors with inductive loop detectors, micro-loop probes, and pneumatic road tubes in addition to video cameras for the efficient management of public roads. However, intrusive sensors may cause disruption of traffic upon installation and repair, and may result in a high installation and maintenance cost. On the other hand, non-intrusive sensors tend to be large size, power hungry, and affected by the road and weather conditions; thus resulting in degraded efficiency in controlling the traffic flow. Traffic lights have been used in academic journals to explain aspects of society. Robinson et al., (2011), explained that traffic lights are one more way 
in which governments can use to control the influx of people. Tody (2011), discussed from a socio-cultural point of view that traffic lights are understood in just about any country where one travels to because we have all learnt what green, yellow and red represent in this context and because the lighting system has been largely accepted globally. John (2013), designed the traffic light with 555- timer in the astable mode to provide clock pulse for the 4017 counter which has ten outputs $\left(\mathrm{Q}_{0}-\mathrm{Q}_{9}\right)$. The 4017 integrated circuit is used as a time delay circle for the traffic control. The output becomes high in turn as the clock pulses are received. Diodes are combined with the outputs of the counter to supply current to yellow and green light emitting diodes (LEDs). Owen et al., (1997), described the real-time traffic adaptive control system (RT-TRACS) as a five basic components; the first predicts traffic conditions given weather conditions, time of day, existing flow, incidents and other traffic factors; the second components defines the sections in the network; the third component selects the appropriate control strategy for the specific section given the traffic conditions that have been predicted; the fourth component implements the strategy; and finally the component performance is evaluated. San (2011), designed a traffic lighting system using the signal control system offset optimization techniques (SCOOT). The system responds automatically to variation in traffic flows base on real - time information fed from detectors embedded in city roadway.

In 1997, Federal Highway Administration (FHWA) developed the urban traffic control system (UTCS) project. The system was installed in Washington DC and was used to test and evaluate advance traffic - control strategies. The system contained $5 / 2$ vehicle detectors whose outputs were used to determine signal timing at 200 intersections. Extensive data processing communications and display capacities were made available to support the traffic control strategy research.

\section{Planning}

Planning is the systematic process of establishing a need and then working out the best way to meet the need, within a strategic framework that enables you to identify priorities and determines your operational principles. Planning means thinking about the future so that you can do something about it now (Janet, 2001).

\section{Need for Planning}

The principal objective of planning in developed and under-developed countries is to increases the basic infrastructural and economic development of a town, region or zone for future purpose. The traffic light control device can provide statistical data for infrastructural planning for any interest group and government. Planning for economic development implies external 
direction or authority which is identified with the government of the state (Gadgil, 2004).

\section{Infrastructure}

Infrastructures are basic amenities that a citizen benefits from the government or group of people in a particular area/region of a given geographical location. These amenities are roads, market, hospital, recreational centre etc. These amenities provide development and fast track socio economic activities in any given area or place when properly planned.

\section{Revenue generation}

The traffic lighting system controls the influx of vehicle into an intersection by displaying the green light permits free right of way. The yellow or amber light is displayed for drivers to get prepared to wait/stop or ready to move into the intersection. Most road user does not adhere to the traffic lightening signal. Any vehicle that is not permitted into an intersection is faulty of the traffic rule, and such vehicle can be capture by the infrared camera. Such drivers are booked and meant to pay stipulated amount to the Government. Also, the infrastructure builds or constructed such as recreational centre and car parks will be used by motorist. The vehicles parked at such places will be used to generate fund and this fund/money can be used for infrastructure maintenance and serves as fund for the Government in meeting the needs of her citizen.

\section{Infrared camera (IR camera)}

An infrared camera is a non-contact electronic device that detects infrared energy (heat) and converts it into an electronic signal which is then processed to produce a thermal image on a video monitor. Any object close to the camera emits infrared energy in form of heat signal. The camera detects and measures the heat signal and shows the apparent surface temperature of the object being measured. The primary source of infrared radiation is the Sun or thermal radiation. The infrared ray lay between the visible and the microwave and it has a wavelength of 8 to $12 \mu \mathrm{m}$. This device uses the infrared ray in the capture of any vehicle that crosses the intersection. The image of the vehicle or person is automatically served in the SD-card or on the hard-disk of the computer system. The hard-disk or the SD-card is memory device which can be access or view by any authorised person.

\section{Materials/components}

Resistors, Variable resistor, I.C (555timer), I.C (4017 Counter), Capacitors, Diodes, LEDs, Switch, battery 


\section{Design}

The traffic lighting control system is designed to control the movement of vehicle into the road intersection. The device comprises of three major sections. The first section is the oscillating signal which employs 555-timer in the astable mode. The output of oscillator is connected to the 4017 counter integrated circuit. The counter turns the Red, Green and Yellow light "ON" and "OFF" according to the timing of traffic phase for each route as shown in figure 1. Secondly the infrared camera is installed at each route of the intersection on the road to capture any vehicle image that obstructs the light rays. As vehicle moves across the intersection, the IR camera detects the heat signal and produces the image of the vehicle on its memory. Thirdly, the traffic lighting device and the infrared camera are network into a computer in order to share the number of vehicle that passes through each intersection and allow electronic communication as shown in figure 2. The communications of different vehicle from different route are saved in the computer saver for ease and free access.

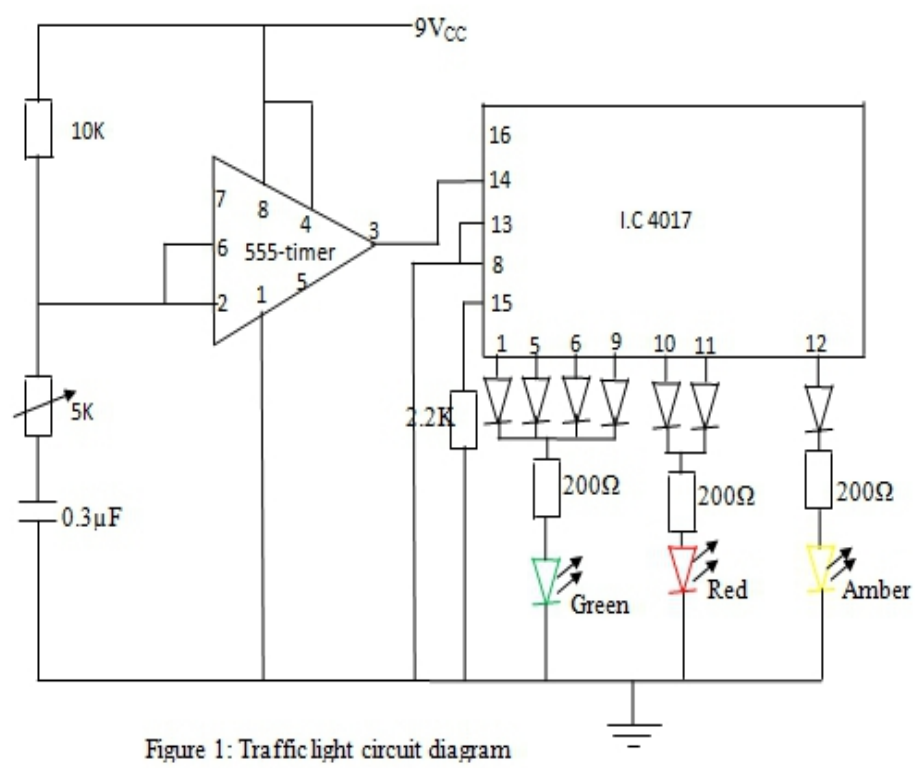




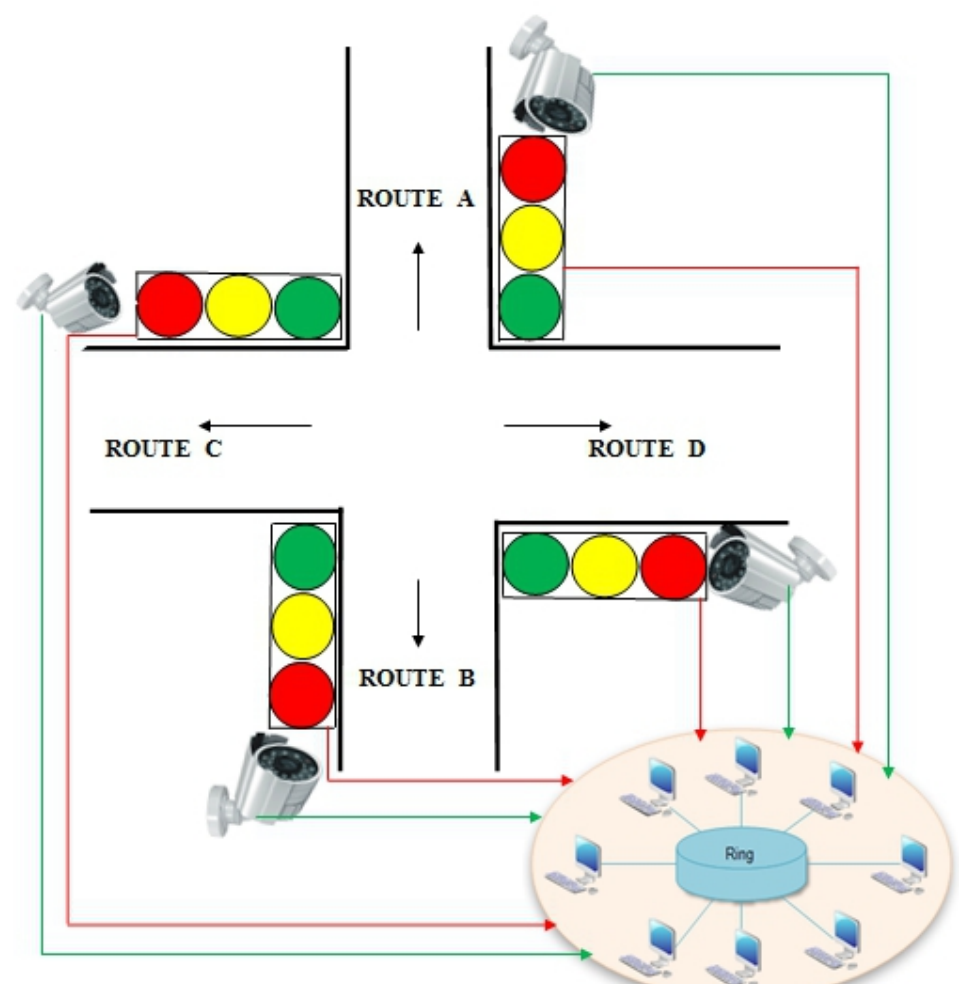

Figure 2: Computer network of traffic light and IR camera

Table 1

\begin{tabular}{|l|l|l|l|l|}
\hline \multicolumn{1}{|c|}{$\begin{array}{c}\text { YEAR } \\
\mathbf{2 0 1 4}\end{array}$} & \multicolumn{1}{|c|}{$\begin{array}{c}\text { No. OF } \\
\text { CAR }\end{array}$} & \multicolumn{1}{|c|}{$\begin{array}{c}\text { NO OF } \\
\text { BUSE }\end{array}$} & $\begin{array}{c}\text { NO. OF MEDIUM } \\
\text { TRUCK }\end{array}$ & $\begin{array}{l}\text { NO OF HEAVY } \\
\text { TRUCK }\end{array}$ \\
\hline January & 108 & 140 & 49 & 86 \\
\hline February & 234 & 168 & 80 & 220 \\
\hline March & 140 & 230 & 94 & 189 \\
\hline April & 160 & 340 & 102 & 194 \\
\hline May & 220 & 446 & 54 & 186 \\
\hline June & 180 & 680 & 109 & 204 \\
\hline July & 192 & 186 & 112 & 228 \\
\hline August & 300 & 94 & 204 & 240 \\
\hline September & 320 & 840 & 340 & 301 \\
\hline October & 420 & 632 & 172 & 340 \\
\hline November & 600 & 105 & 168 & 360 \\
\hline December & 1502 & 940 & 441 & 780 \\
\hline Total & 4,376 & 4,801 & 1,945 & 3,328 \\
\hline
\end{tabular}


Table 2

\begin{tabular}{|l|l|l|l|l|}
\hline $\begin{array}{c}\text { YEAR } \\
\mathbf{2 0 1 5}\end{array}$ & \multicolumn{1}{|c|}{$\begin{array}{c}\text { No. OF } \\
\text { CAR }\end{array}$} & $\begin{array}{c}\text { NO OF } \\
\text { BUSES }\end{array}$ & $\begin{array}{c}\text { NO. OF MEDIUM } \\
\text { TRUCK }\end{array}$ & $\begin{array}{c}\text { NO OF HEAVY } \\
\text { TRUCK }\end{array}$ \\
\hline January & 86 & 101 & 112 & 146 \\
\hline February & 120 & 88 & 104 & 189 \\
\hline March & 98 & 69 & 96 & 48 \\
\hline April & 104 & 114 & 212 & 69 \\
\hline May & 202 & 180 & 314 & 194 \\
\hline June & 420 & 160 & 86 & 68 \\
\hline July & 320 & 191 & 108 & 102 \\
\hline August & 410 & 205 & 59 & 130 \\
\hline September & 501 & 212 & 70 & 145 \\
\hline October & 63 & 300 & 186 & 240 \\
\hline November & 198 & 384 & 1110 & 290 \\
\hline December & 1050 & 794 & 1320 & 456 \\
\hline Total & 3,572 & 2,798 & 3,777 & 2077 \\
\hline
\end{tabular}

\section{Evaluation}

$$
\text { Mean }(\mathrm{x}) \text { no. of cars }=\frac{\text { total no. of cars }}{\mathrm{n}}
$$

Where $\mathrm{n}=$ total numbers of month

$$
\begin{aligned}
& =\frac{4376}{12} \\
& =365 \\
& \begin{aligned}
\text { Mean } & (\mathrm{x}) \text { no. of buses }=\frac{\text { total no. of buses }}{\mathrm{n}} \\
& =\frac{4801}{12} \\
& =400
\end{aligned}
\end{aligned}
$$

Mean (x) no. of small truck $=\frac{\text { total no. of small trucks }}{\mathrm{n}}$

$$
\begin{aligned}
& =\frac{1945}{12} \\
& =162
\end{aligned}
$$

Mean $(\mathrm{x})$ no. of long trucks $=\frac{\text { total no. of long trucks }}{\mathrm{n}}$

$$
\begin{aligned}
= & \frac{2077}{12} \\
= & 173
\end{aligned}
$$

\section{Discussion of results}

\section{Discussion}

The statistical data from the tables are results of images of vehicles captured by the IR camera as showed in figure 2, as the traffic light gives right 
of way to any particular route. The total numbers of vehicles entering the town's intersection per month is shown in the table (1-2) for year 2014 and 2015. From these tables the month of December has the highest number of vehicles because it is the month of festivity. Figure 2 shows how the infrared (IR) camera and the lightening system are interface with the computer network. The images of vehicle are stored in the computer memory and this stored data can be retrieve or view by any individual or Government for infrastructural planning. The traffic jam in most cities during festive period is very dense and a traffic network system can be used to decongest this time delay occasion on the route.

\section{Conclusion}

The design of the traffic light with infrared camera network has a good performance in the timing duration and production of image by the IR camera. When properly installed, the data stored in the computer memory can be access. Each route captures the images of vehicle entering into the intersection. The data can be used as a physical feasibility study of the numbers and type of vehicle that enter into any route intersection. It will serves as guide for infrastructural planning for the creation of standard road, market and recreational center for towns and cities. It can also serves as means of revenue generation for the government when traffic offenders are meant to pay fine for violating the traffic.

\section{Recommendation}

The availability of the original components was a major concern from the vendor. Some of the materials cannot be source locally. Epileptic power supply was experienced during soldering. The amount of power supplied determines the amount of heat applied to the soldering lead and it determines the joint formed at the contact point.

\section{References:}

1. Bonaventure, O (2011). Computer networking; Principle, protocol and practice, N.Y, USA.

2. Baykov G. (2004), Planning and cupulsory purchase act, England

3. Christina P. (2014), Landscape and urban planning, Madison, USA.

4. Cheung, S. Y, Dundar, B. Ganesh, S. Tan, C. W. and Varaiya, P. (2005). Traffic measurement and vehicle classification, 84th Annual Meeting Transportation Research Board, Washington, D.C.

5. Knaian, A. N. (2000), A wireless sensor network for smart roadbeds and intelligent transportation systems, Massachusetts USA.

6. Owen, A. M., Milner, B., Petrides, M. and Evans, A. C. (1996), Memory for object-features versus memory for object-location: a 
positron emission tomography study of encoding and retrieval processes. USA.

7. Robinson, $\mathrm{P}$ (2011). Technology forcasting and social change, Vol. $78, \mathrm{P}_{\mathrm{P}} 756-768$

8. Robinson, P., Heitmann, S. and Dieke, P.U. (2011), Research themes for tourism,Wallingford Oxfordshire; Cambridge.

9. San, D. (2012), Signal control offset Techniques, Kingsville, USA.

10. Schutter, B and Moor, B (1998), Optimal traffic light control for a single intersection, European Journal of Control, Vol. 4, Pp. 260-276.

11. Thorndike, A.N, Riis, J. and Sonnenber, L.M (2014), Traffic light labels and choice, American Journal of preventive medicine 46 (2).

12. Thody, P. Introducing barthes; A graphic guide, reprint edition, Icon books Ltd. London; USA.

13. Journal of information science and engineering (2010), Vol. 26 Pp,753 $-768$

14. Zheng, Y. and Cao, J. ((2007), Protocols for traffic safety using wireless sensor network, Computer Science, Vol. 44, Pp. 37-48. 